\title{
3.3 Constructions of Environmental Issues in Scientific and Public Discourse
}

\author{
Andreas Metzner
}

in: Mueller, F.; Leupelt, M. (Eds.):
Eco Targets, Goal Functions and
Orientors; Berlin, Heidelberg, New
York (Springer Publishers) 1998,
pp. 171-192 (preprint version)

\section{Abstract}

We have two possibilities to explain why there is continuing change on the public agenda of environmental issues. Either the changes are viewed as reactions of social actors to real alterations of the environment, or they are viewed as reactions to alternating cultural conditions. The willingness of society to recognize and solve environmental problems depends upon the claims-making activities of differently motivated social actors in public discourses. The sciences produce cognitive and interpretative claims, focusing either on pure description or giving evidence for the need to act. The deconstruction of scientific claims may lead to a relativistic overall devaluation of knowledge needed to encounter environmental problems.

A model is introduced that integrates socio-ecological approaches with cultural studies oriented ways to treat societies and their environment. The necessity to built complex procedures of eco-social regulation increases historically along with the growing complexity and differentiation of societies. Society has to determine environmental limits and goals, which are not directly observable, but need to be reconstructed and agreed upon. If it is the task to mediate environmental problems, the more general concepts of ecosystem integrity or environmental health perform better than the rather specific goal function concepts.

\subsubsection{Introduction}

Environmental problems do not establish themselves on the public agenda. "They must be 'constructed' by individuals or organizations who define pollution or some other objective condition as worrisome and seek to do something about it" (Hannigan 1995, p 2). In this regard, environmental problems are not very different from other social problems such as child abuse, juvenile crime or AIDS. But there are, however, a few notable differences: Social problems derive much of their rhetorical power from moral rather than from factual arguments. 
Environmental problems have a more imposing physical basis than social problems, which are rather rooted in personal troubles growing into public issues (Hannigan 1995, p 38).

A good example for the interaction of physical and social aspects is the 'Love Canal' case, a settlement built on top of a hazardous waste-dump in New York State (Fowlkes and Miller 1987; Mazur 1991). Toxic vapors emerged from the subsoil and entered into people's homes, but as long as health defects were not apparent, and not connected with the toxic wastes, nothing happened. There was neither a demand for action, nor were there any protests-in other words: there was no problem. The difference between a scientific-objectivistic and a constructivistic, cultural-studies-oriented concept of a problem becomes quite apparent here. The natural scientist gives an objectivistic description of the facts, determines the type and concentration of the toxins in the soil, and in the bodies of the persons affected, and grasps this as the problem. The social scientist, however, endeavors to treat the problem by investigating the action-leading-concepts of human participants, the state of consciousness of the individual subjects, and the motives of interacting social participants. "Social problems are what people think they are" (Spector and Kitsuse 1987, p 73).

In principle, we have two possibilities to explain why there is continuing change on the agenda of environmental issues. Either the changes are viewed as reactions to the alterations of the environment, or they are viewed as reactions to alternating public attitudes (Ungar 1992). The first approach concentrates on problems of eco-social metabolism and societal (re)production, the other on phenomena of social construction and perception of environmental issues. The social sciences orientate to either of these leading themes; they do exist simultaneously inside (environmental) sociology (Dunlap 1993; Dunlap and Catton 1994).

The development of methods of environmental management and some basic rules for using environmental resources according to the principles of sustainable development (Constanza, Daly and Bartholomew 1991; Huber 1995, pp 49; WCED 1987, pp 44-60; Vellinga, de Groot and Klein 1994) are examples for the first main leading theme. In order to identify the necessary requirements and strategies of improvement, this approach poses the following questions: What are the social causes of environmental changes leading to degradation, and what are the social effects of the emerging environmental problems? The difference in attention paid to anthropogenic climate changes in contrast to the low attention paid to the problem of worldwide soil erosion exemplifies the importance of the second main leading theme: Why are certain environmental phenomena diagnosed as problematic and brought towards a solution, while others - factually not less 'problematic' or 'risky' events - are hardly or not at all noticed? 


\subsubsection{Understanding Environmental Problems and Technological Risks}

\subsubsection{The Constructivistic Approach and its Critics}

The constructivistic approach comprehends "risks" as constructs of social communication and explains "the increase of environmental and technological risks" through cultural processes of change. Douglas and Wildavsky $(1988, \mathrm{pp} 10)$ hold that the balance of power between the central cultural institutions (including the market and the hierarchy) and the "sect" as the socially peripheral subculture has shifted so eminently that the risk-aversions of subcultural, social movements (with "egalitarian" life-styles) have turned into the prevalent subject-and thereby predominant reality-for the developed industrial societies.

Because the approach has freed risk assessment from of the grip of purely technological-scientific and psychological handling, it has its merits. It needs to be mentioned, however, that it merely deals with risk constitution, not with (social and industrial) risk production. Therefore, it (mis)understands ecological criticism as anti-industrial and anti-modernistic. The objective contents of environmental problems is simply neglected. The ecological problems do not appear as a threat to "society", but the environmental movement does, which challenges the established institutional order and threatens its beneficent functioning.

In spite of all psychological theories that try to reduce the characteristic of the perception of environmental problems to patterns of individual psychology (Jungermann and Slovic 1993), it remains unexplained why a dispersion of divergent risk evaluations and different assessments of endangered (environmental) goods - spread over the whole population - are found. Sociological explanations of this observation are referring to divergent utilization interests of the participants, to disparate states of knowledge, to different frames of rationality, and to deviating patterns of cultural values.

Its (exclusive) explanation claim of the constructivistic approach closes the gap left by risk psychology. Risk psychology provides an understanding of individual differences in recognizing and accepting risks, but it remains to be answered, why a variance of certain patterns of risk preferences and risk aversions can be observed within the population. The answer is thought to be found in the different sociocultural contexts, in which individuals live, and in the orientation of the thinking and acting of individuals towards institutions (Thompson, Ellis and Wildavsky 1990). The different biophysical conditions of the individuals' environment and the latter's ecological alteration do not play a role, not even as a constitutive element within a multi-factorial explanation model of particular risk cognition.

Sociologically, it is by all means imperative to inquire into the structures of the material production of the "risk-society" (Beck 1986). Instead, culture is presented as the only explanation. The (rhetorical) question "are dangers really 
increasing or are we more afraid?" (Douglas and Wildavsky 1988, p 1), can only be answered in one way: "We are more afraid!". The phenomenon of "growing environmental and technological risks", which requires further explication, is merely diagnosed as the result of growing sensibility towards these risks, caused by processes of cultural change. Thus, Douglas and Wildavsky represent a radical thesis: cultural processes of change put the individual into a state of uncertainty. The individual looks for an object to project its anguish onto and finds it in environmental and technological risks. This thesis implicates that the (environmental) anxieties are actually misleading and unfounded. This approach is decisionistic in so far, as processes of the industrial-technological (re)production and formation of society cannot be investigated. They are understood as something extra-societal - similar to the factors of the "natural" environment. According to the dogma "social matters can be explained only by social phenomena", they are no longer to be comprehended as subjects of social sciences research.'

Rejecting this mono-dimensional approach, I prefer a combined, multiple approach. The perception of technological risks and environmental problems, of social risk-preferences and -aversions may depend on

- socio-cultural changes (e.g., post-materialism, pluralization of life-styles);

- scientific-technical progress in the detection and measurement of potentially harmful substances,

- growing technical capacities of diagnosing and treating environmental and technological problems;

- technological alternatives for a more sustainable utilization of nature;

- changes in the state of the environment or in the intensity of risks, be they observable, effective or apparent.

\subsubsection{The Realistic Approach and its Critics}

The realistic approach comprehends "risks" as objective elements of interaction between nature and society. It explains the "increase of environmental and technological risks" through the intensification and extensiveness of nature's utilization. According to Dunlap (1993) the environment has to fulfill three essential functions for society, namely: a) to provide it with resources, b) to absorb its refuse, and c) to serve as "living-space" and habitat of man. If an environment is used by one function, the other two are impaired. Usufructuary competition and

\footnotetext{
${ }^{1}$ This exclusion of a substantial research-perspective takes place with different accentuations also in the systems-theoretical treatment of environmental, technological and risk problems in so far as the analysis runs under the communications-theoretical premises of the sociology of Luhmann (1984, 1986, 1991). The disadvantage of this methodological exclusive approach, that assigns itself lately as "constructivistic systems theory" (Japp and Krohn 1996), lies in the fact, that the possibilities to intensify an inter- and trans-disciplinary research - as they are offered in the context of the "general systems theory" - are neglected in favor of a pure "sociologism".
} 
social conflicts may arise. The ecological systems are affected by pressures, which may in extreme cases disrupt the capacity of the ecosystem to regenerate and function. The simultaneous expansion of all three functions leads to a transgression of the global carrying capacity and of the ability of the environment "to withstand" the stress. Dunlap (1993) infers that an original ecological problem of the society subsists, manifesting itself in increasing practical problems and growing risks fulfilling the three basic functions. This problem will remain incomprehensible, if it is understood merely in the framework of the "construction of social problems" as a genuine phenomenon of social cognition and communication. The growing social attention towards environmental and technological risks is therefore in essence a responsive reaction to their actual increase.

A constructive critique of Dunlap's statements has to make - amongst others - ecological points because his description of nature lacks an elaborated ecosystemic argument. His view does not accommodate the fundamentally dynamic nature of ecological phenomena. The distinction between ecologically harmless utilization of resources or smaller scale "disturbances" and irreversible damages remains systematically unexplained. Nor does Dunlap's approach consider positive interactions between different types of the utilization of nature, for instance between adapted agriculture and biodiversity.

Roughly speaking, it is the strength of Dunlap's approach to develop footholds for integrated ecological and sociological problem analyses and crisis management strategies. The weak point is its inability to address aspects of the communicative processing of perceived problems. He does not take up the following questions: Which socio-economic achievements produce relevant material and energy flows? Which functional prerequisites are found in supratechnological infrastructure-systems (Mayntz and Hughes 1988; Gras 1993)? Which institutions and media are needed for the control of these systems (Ayres and Simonis 1992)? In connection with a model of functional societal differentiation (Luhmann 1984, 1986, 1991), these questions, however, have to be answered, before another question can be tackled: Why are certain environmental problems intensely heeded while others - sometimes "objectively" equally important ones - are neglected?

\subsubsection{Claims-making activities: assembling, presenting and contesting environmental issues}

Hanningan (1995) presents an analytical frame that allows analyzing processes of the construction of environmental issues related to the different functions of sciences, the mass media and politics in the field of public discourse. According to Hannigan, the willingness of society to recognize and solve environmental problems rests primarily upon the claims-making activities of a handful of 'issue entrepreneurs' in science, in the mass media and politics. He identifies three key 
tasks in the definition of any environmental problem: assembling, presenting and contesting, each of which carries its own activities, opportunities and pitfalls.

Table 3.3.1. Key Tasks in Constructing Environmental Problems (Hannigan 1995, p 42)

\begin{tabular}{|c|c|c|c|}
\hline & Assembling & Presenting & Contesting \\
\hline $\begin{array}{l}\text { Primary } \\
\text { activities }\end{array}$ & $\begin{array}{l}\text { discovering the problem } \\
\text { naming the problem } \\
\text { determining the basis of } \\
\text { the claim } \\
\text { - establishing parameters }\end{array}$ & $\begin{array}{l}\text { - commanding atten- } \\
\text { tion } \\
\text { - legitimating the claim }\end{array}$ & $\begin{array}{l}\text { - invoking action } \\
\text { mobilizing sup- } \\
\text { port } \\
\text { - defending owner- } \\
\text { ship }\end{array}$ \\
\hline Central forum & - Science & - Mass media & - Politics \\
\hline $\begin{array}{l}\text { Predominant } \\
\text { 'layer of proof' }\end{array}$ & - Scientific & - Moral & - Legal \\
\hline $\begin{array}{l}\text { Predominant } \\
\text { scientific role(s) }\end{array}$ & $\begin{array}{l}\text { - Trend spotter } \\
\text { - Theory tester }\end{array}$ & - Communicator & $\begin{array}{l}\text { - Applied policy } \\
\text { analyst }\end{array}$ \\
\hline Potential pitfalls & $\begin{array}{l}\text { - lack of clarity } \\
\text { ambiguity } \\
\text { conflicting scientific } \\
\text { evidence }\end{array}$ & $\begin{array}{l}\text { - low visibility } \\
\text { - declining novelty }\end{array}$ & $\begin{array}{l}\text { - co-optation } \\
\text { - issue fatigue } \\
\text { countervailing } \\
\text { claims }\end{array}$ \\
\hline $\begin{array}{l}\text { Strategies for } \\
\text { success }\end{array}$ & $\begin{array}{l}\text { creating an experiential } \\
\text { focus } \\
\text { - streamlining knowledge } \\
\text { claims } \\
\text { - scientific division of } \\
\text { labour }\end{array}$ & $\begin{array}{l}\text { - linkage to popular } \\
\text { issues and causes } \\
\text { - use of dramatic verbal } \\
\text { and visual imagery } \\
\text { - rhetorical tactics and } \\
\text { strategies }\end{array}$ & $\begin{array}{l}\text { - networking } \\
\text { developing tech- } \\
\text { nical expertise } \\
\text { opening policy } \\
\text { windows }\end{array}$ \\
\hline
\end{tabular}

When scientists engage in claims-making activities, they are mainly handicapped by a combination of scholarly caution, excessive use of technical jargon and inexperience in handling the media (Hannigan 1995, p 44). In order to fill this gap, popularizers are needed - individuals, such as Jeremy Rifkin, or organizations, such as Greenpeace. Accordingly, the success of the claims-making activity by Greenpeace lies not so much in its ability to construct entirely new environmental problems, but rather in its genius to select, frame, and elaborate scientific interpretations that might otherwise have gone unnoticed or would have been deliberately glossed over (Hannigan 1995, p 44, in reference to Hansen 1993, p 171).

In sum, Hannigan (1995, pp 54) identifies six factors necessary for the successful construction of an environmental problem:

1. Scientific authority for the validation of claims.

2. Existence of 'popularizers' who can bridge environmentalism and science.

3. Media attention, where the problem is 'framed' as novel and important.

4. Dramatization of the problem in symbolic and visual terms.

5. Economic incentives for taking positive action.

6. Emergence of an institutional sponsor who can ensure both legitimacy and continuity. 
The success of environmental movements is one facet of the discrepancy between growing environmental consciousness by successful problem construction and continuing, ecologically harmful behavior (Schluchter and Metzner 1996). Their success is considerable less noteworthy in getting their policies institutionalized, especially, where these policies might require the reallocation of resources away from potent capital interests and inflexible bureaucratic actors (Hannigan 1995, p 49; in contrast to Maxeiner and Miersch 1996).

\subsubsection{Science, Politics, and the Public}

Starting from the observation that hardly any environmental problem, e.g., acid rain, loss of biodiversity, or dioxin poisoning, does not have its origin in a body of scientific research, the orthodox way how science sees itself is scrutinized. The task of traditional science seems to be the search for truth with the goal to obtain a clear reflection of nature, as free as possible from any social and subjective influences that might distort the 'facts'. Nevertheless, the sciences are not merely a medium to which one refers in order to construct environmental problems. Frequently, they become the target of environmental claims themselves, for instance, in the case of the potentially harmful effects of genetic engineering. A paradoxical situation originates, because environmental argumentation has to presuppose the credibility of scientific expertise when defining these problems. When fighting against science-based industrial projects, however, they are forced to doubt the technocratic rationality of science by referring to 'social rationality' or folk wisdom (Perrow 1984).

Science has become dependent on social and political processes. Whatever is on the political agenda gets researched, since scientific knowledge is produced, where research funds are available. The consequences of these developments have two symptoms: the politicalization of science and the scientification of politics (Weingart 1983). One can assume that the scientification of politics is less problematic for the scientific community than the politicalization of science because politics may improve through better expertise. But the conduct of politics - that is mediation of problems, balancing of interests, etc. - is more difficult when scientific experts claim the objective truth of their findings. Furthermore, the credibility of science is undermined when experts present different results dealing with the same issue. Consent in the scientific community and the lack of scientific controversy influence the public credibility of science profoundly. This way, a certain pressure emerges to reduce the normal and important scientific controversy in favor of more consensual and coherent statements on part of the particular scientific community in order to gain public resonance and political support. The relationship of scientification and politicalization carries many more critical tendencies, which cannot be explicated here.

To gain a better understanding of science's role in modern societies, it is useful to make a distinction between cognitive and interpretive claims, corresponding 
with the concepts of 'instructional' and 'operational knowledge', which means the difference between "knowing how to do" and "knowing what to do". On the one hand, there is the pure description of a situation, e.g., the charge of fresh water ecosystems with sulfuric acids. On the other hand, there is the purpose to give evidence for the need to act (often mediated with adequate semantic constructions like a 'critical load' of an ecosystem that implies the need not to exceed its limits) (Alcamo 1984). The activity of scientists does not end, however, with making knowledge claims. They also routinely construct ignorance claims highlighting 'gaps' in the available knowledge in order to promote the necessity of further research, or to retard unwanted or disturbing political action because not enough hard data exist to justify legislative or administrative activity (Hannigan 1995, p 77).

Table 3.3.2. Uncertainties regarding processes of global climatic change

Uncertainty regarding the mechanisms of the effect. Does the sea-level rise? Will there be more storms?

Uncertainty regarding anthropogenic causation. Does the variance perhaps lie within the range of natural fluctuations? Are, e.g., the effects of a volcanic eruption bigger?

Uncertainties related to the time scales of prognosted changes and to the localization in space. Are they detailed or rough, what is the speed of the delocalization of eco-zones on the earth's surface, where will extreme weather events become more frequently?

Uncertainty regarding the socioeconomic and political repercussions. Will there be crop shortages? Will there be mass migrations and conflicts about eco-refugees? Do higher energy prices have a negative effect on the growth of the gross national product, or do they trigger a technical breakthrough in the direction of higher energy and resource productivity?

Uncertainty regarding the efficiency of countermeasures. Does a $25 \%$ reduction of $\mathrm{CO}_{2}$ production have any considerable climatic effect and when does it occur? Are the expenses of the reduction greater than the costs of the prevented dangers?

The uncertainties of forecasting the effects of global change are a good example in case (Bechmann et al. 1996). Concerning these uncertainties, we have to be aware of the phenomenon, that science has undergone a metamorphosis from a 'classic' (mechanistic) to a 'transclassic' (postmechanistic) science (Prigogine and Stengers 1981; Krohn, Küppers and Paslack 1987). In order to investigate this complex matter of real world phenomena, it is not sufficient anymore to 'construct' (mono)causal linkages between cause and effect under the 'ideal' circumstances of the scientific laboratory. Instead, it is necessary to work with models including a high number of factors and parameters. The models show different kinds of dynamic behavior according to alternating starting points and conditions, and according to different algorithms describing different potential causal linkages. There is no other - or better - way to verify the prognostic ca- 
pacity of such models than testing the validity of underlying assumptions and by simulating past or present processes that can be compared with empirical data.

Regarding the growing necessity to deal with the effects, problems, and risks emerging from the relationship between human societies and their ecology, science loses more and more the character of a pure basic science and rather gains some characteristics of applied science (such as medical and engineering science). Furthermore, the very idea of science itself has changed. In former times, science was thought to produce media for the increasing human domination of nature. Today science has to deal already with the problems of man's successful appropriation of nature - it has turned into a reflexive science (Beck, Giddens and Lash 1994; Lash, Szerszinsky and Wynne 1996). Thus science works in the context of a reflexive industrialization, which needs to master the charges and after-effects of the conventional modernization (Mol 1995).

The acceleration of the adaptive processes of social institutions (related to technological innovations, economical restructuring, cultural changes, and environmental alterations) poses a great challenge to politics. Reactive politics that intervenes only when manifest damages occur, is systematically late. A proactive politics could be effective in time, but it is forced to work with uncertain hypotheses regarding the problems or corrective measures. According to the principle of precaution, even scientific uncertainty is no excuse for the delay of protective measures concerning ecologically destructive processes. To be useful as reference points for social practice, it is not necessary that models are scientifically complete in detail. In view of the ever lasting hypothetical character of all scientific knowledge, as Critical Rationalism has pointed out (Popper 1982), completely detailed models are impossible as it is. As (even temporary) points of reference it is sufficient that the models be more coherent and covering more observations and experiences than concurrent action-leading cognitive maps (Fischer-Kowalski 1991).

\subsubsection{Scientific Advertisement}

In politics top down and bottom up oriented approaches are linked to different world views. One side is convinced "we need more democracy" because "the people know best" how to attain a growing public welfare. The other side underlines the necessity of an institution, capable to integrate vested interests and to force decisions when necessary against resistance.

The advisory function of science has to change while reacting either to 'top down' or 'bottom up' approaches. Several media can be used to implement political decisions, to formulate political targets, or to influence processes of decision-making. Of these, money, power, and knowledge are three most important ones. Knowledge is the specific medium of science. As on other markets, the impact of ecological knowledge depends on demand as well as on the way this medium is offered. Furthermore, there is competition between ecologists and often publicly better-established - economists in advertising their political ideas 
in the decision-making process. Conflict arises, for instance, in the debate over the need for economic adaptation to the ongoing 'globalization' of the world market. This debate distracts attention from discourses that pled for ecologically inspired future scenarios, such as "Sustainable Netherlands" (van Brakel and Builtenkamp 1992) or "Zukunftsfähiges Deutschland" ('Future Oriented Germany') (BUND and MISEREOR 1996).

The course of the concurrent debates suggests to make ecological knowledge more attractive. To strengthen its position, it is of growing importance to introduce competencies of ecology into interdisciplinary working groups and projects. To demonstrate the positive effects on ecological knowledge, social and economical advantages or positive effects to the quality of human life should be mentioned frequently. Ecology as a scientific discipline should in each case try to satisfy the top down as well as the bottom up induced demand for advertising and expertise. Ecology should provide environmental knowledge understandable for all participants in public discourse and lucid management schemes. Its models should be far-reaching and complete to enable overview and orientation.

\subsubsection{Shared Responsibility and the Impact of the Sciences}

Natural and social sciences should take equal responsibility for the alteration of ecologically relevant social practices. Not only the claims making activities of objectivistic sciences are responsible for environmentally destabilizing human actions. By pointing to the necessary relativity of such scientific truth claims, or by deconstructing the social genesis and social functions of these claims, subjectivist and constructivistic studies may invalidate possibly correct and practically important knowledge. On the other hand, the deconstruction of scientific knowledge shares responsibility for the validation of the incorrect. Take the quarrel about global environmental changes. Several authors stress the uncertainty of scientific data, models and prognoses (Bailey 1995; Wildavsky 1995). Their work would be misleading, however, if (ordinary) people would think "OK then, scientists construct their knowledge as they want", and deny the need for any action. In this context we have to recognize that the own interests of scientists are a decisive factor as the need of the acquisition of research-funds has become overwhelming. This effect has been reported, e.g., in the case of the climate research community and its 'construct': the greenhouse-effect. The ideologycritical motive to deconstruct knowledge claims, however, can lead to the unintended consequence of increasingly opportunistic use of expertise and research. The uncontrollable use of science by vested interest is nothing else than the direct opposite of the original motive. 


\subsubsection{Modeling Ecology and Society}

In general, models striving to integrate natural and social processes cannot consist exclusively of simple cause and effect relations. Between a physical event (or condition) and its social effect (or consequence) lies the contingency of human action and perception. The notion of contingency refers to the distinction of animal behavior and human action ${ }^{2}$, as it was established by Max Weber, several anthropologists, and in social systems theory by Parsons followed by Luhmann ${ }^{3}$. Contingency means that it is possible for humans to act in various ways rather than having to act in one way.

Questioning the relationship of social and natural systems, we have to recognize two prejudgements. First, social systems are following other, self-generated and symbolically organized laws than natural systems. Second, social systems, nevertheless, depend upon ongoing processes of interaction with natural systems. They are emergent entities built up of populations of human organisms that have to be stabilized through the metabolism of society and environment. Following these prejudgements, we ask: How far are social systems heteronomous ('material' entities) and how far are they autonomous ('cultural' entities) related to their biophysical environment?

\subsubsection{Symbolical and Material Dimensions of Social Systems}

The concept of "socio-anthropogenesis" (Leakey 1993; Löther 1988) signifies that the evolutionary process of anthropogenesis and the evolvement of a society capable of sociocultural evolution happened concurrently and interdependently. Every "animal-society", such as "monkey-societies", lives as a natural unit in a natural environment. In the transition towards human society, these two dimensions do not vanish but additionally become symbolically constituted. Societies are no longer merely real existing populations in real existing environments. They become symbolically existing societies (described by themselves) in a symbolically existing (socially described) environment. Human society and ecological environment exist in a physical-natural as well as in a culturalsymbolical sense.

Neglecting these interdependencies, e.g., by postulating the independence of the autopoiesis of sense-processing systems (such as social systems or systems of individual consciousness) from human actors, which are viewed merely as parts

\footnotetext{
${ }^{2}$ We are using this distinctive concept further on, well knowing that in the light of recent primate research, especially related to questions of the capacity to lem, use and generate elements of symbolic (sign) language, and to the capacity to traditionalize or enculturate techniques of how to use and make tools, a sharp diversion between animals and humans no longer exists.

${ }^{3}$ The term 'double contingency' as introduced by Luhmann indicates that there is neither a fixed action (from ego) nor a re-action scheme (from alter-ego). The reduction of the complexity of the given possibilities to (re)act works by means of (mutual) expectations, condensating to norms, values and institutions, stabilizing clusters of corresponding actions that generate (via order-from-chaos-principles) coherent social systems (Luhman 1984).
} 
of their environment, like Luhmann (1984) does, leads on the one hand to mystifications, such as a re-ontologization of systems-theory, and gives up an analytical definition of 'system' in favor of an idealistically biased ontological viewpoint. On the other hand it leads to a sharp division between social and ecological system conditions of human existence: They cannot be analyzed as interdependent complements, and the integral unity of the human actor fades away. Rather, 'social systems' are social constructions, born out of communicative processes between human actors, serving their orientational needs.

\subsubsection{Societies and their Ecology: How to Describe Divergencies and Con- vergencies?}

In the following model of interactions and relations between human society and ecological environment (Fig. 3.3.1), I plead for the concept of a two-stage system of human societies, which does not comprehend the latter merely as sociocultural units, but also comprehends them in a naturalizing way as ecological entities (Metzner 1993, 1994).

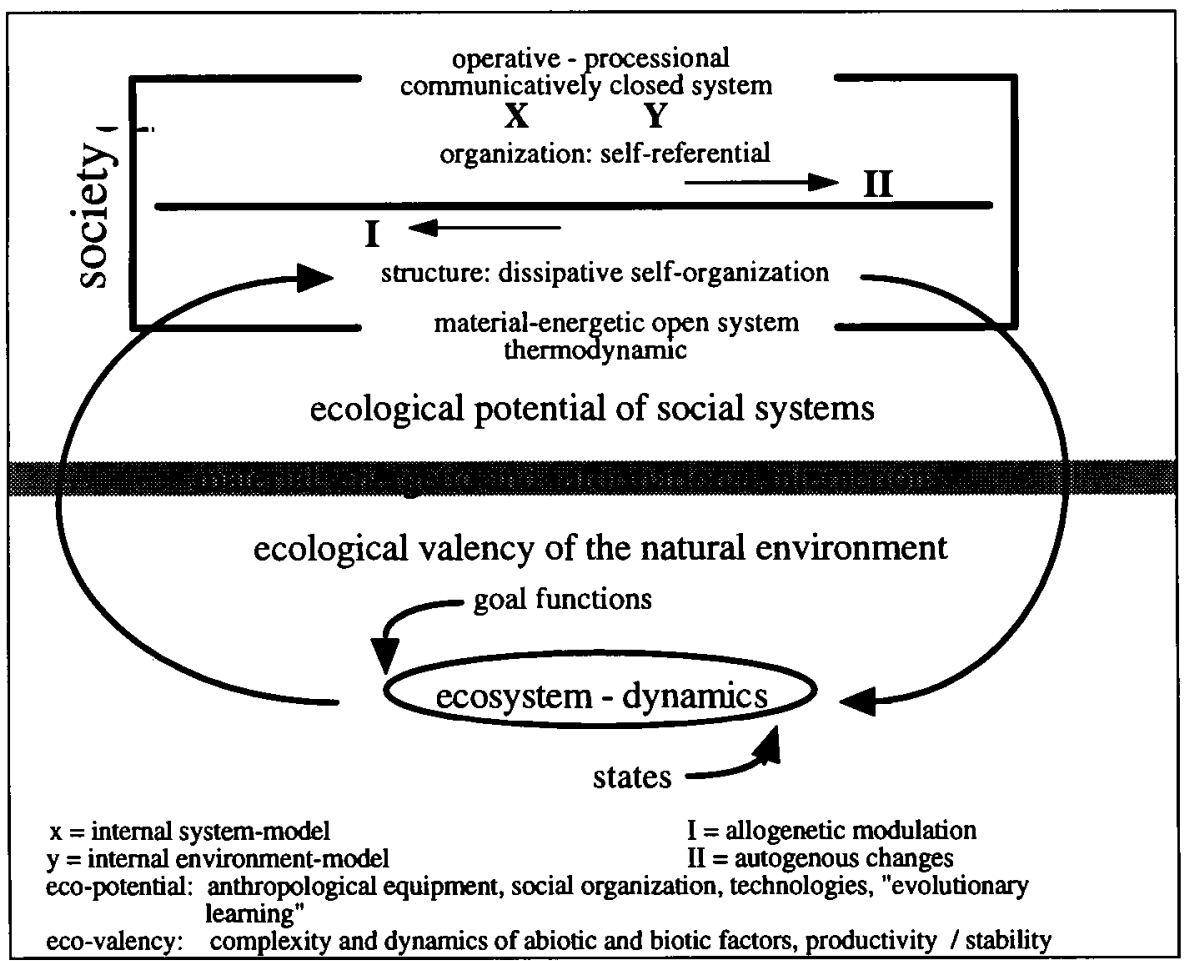

Fig. 3.3.1. Ecology and Society: A Two-Stage Systems Model 
Because they are materially and energetically open systems, human societies are directly (retroactively) affected by (natural or self-induced) environmental changes. They are, however, as operatively closed systems, only indirectly related to their ecological environment. They are able to notice, pass over, or suppress environmental changes judging by their own affectedness. They can deny these phenomena or interpret them as problematic or risky. They can preserve the 'tried and tested', or accomplish learning processes capable to reorganize economic, political or scientific behavior. When learning processes and behavioral changes take place, the effectiveness and the consequences of human actions change as well: the substantial connection between environment and society is affected.

All living things are elements of ecological systems, they have a metabolism and consume exergy. The co-evolution of species, e.g., of the different populations of one habitat, generates continuing dynamics towards an optimization of 'their' ecosystem. This optimization is characterized by two qualities:

1. metastability (a high probability of the populations' continuing existence) and

2. a configuration of the flow of substances and energies that results in an actual closing of the circuits, and in an energetic intensification of the utilizationcascades.

Only human beings have, in the course of their social development, left this path of co-evolution. But this does not change man's integration into the structural organization of ecological systems.

\subsubsection{Reconstructing Issues: Ecological Limits and Goal Functions}

To return to a 'metastable' development of society, it appears necessary to find ecological limits to human actions. Integrated goal functions may help identifying these limits. Procedures regulating the population density, the utilization of ecological resources, and limiting non-intended anthropogenic alterations of the environment can be found in all cultures (Weichhart 1989). In an "ecofunctional" sense, these procedures represent attempts to install self-selected limits to the interaction with nature, before nature itself manifests limits, for instance, when the carrying capacity is exceeded. If critical limits are surpassed, ecological chains of effects are activated that may lead to catastrophic dynamics of unknown proportions. Returning to non-critical conditions may be impossible without paying a high price in terms of human life, public health or common wealth. Besides this preventive function, the regulation procedures have an optimizing function, namely to use ecological resources efficiently, durably and sustainably. 
To work out suitable regulation procedures, it is necessary to integrate the particular performance and development of ecological systems conceptually into the communicative structure of socio-cultural institutions. Society has to encode its perception of its own state of well-being and goal-attainment, along with an adequate perception of environmental states, limits of appropriation, and effective allocational principles. On grounds of internal contradictions between different societal subsystems, however, an adequate and up-to-date system of socioecological regulation procedures is missing. The question is whether an integrated goal function concept could be a valuable contribution to this challenge.

\subsubsection{How to Determine Limits: Biophysical or Sociocultural?}

The analysis of the construction of environmental issues revealed so far that from natural science as well as from social science approaches valuable insights can be gained. Instead of employing the approaches in an isolated fashion, a complementary use of the approaches is required. Still, it has to be analyzed in detail, how ecological limits, e.g., to anthropogenic emissions of greenhouse gases, can be determined. As part of the natural greenhouse effect, carbon dioxide is considered a good thing because it is an crucial substance in the climatic life support system. As part of the anthropogenic greenhouse effect, carbon dioxide turns into the opposite. But what is the point of reference for an emission reduction goal? Is it the 'natural' concentration of $\mathrm{CO}_{2}$ in the atmosphere (yet, 2, 10 or 100 thousand years ago), the (maximum) emission quantity that is considered 'neutral to the climate', the economically optimal ratio of marginal utility/marginal costs, the emission quantity that is necessary for mankind to survive, or a concentration that is deemed "optimal" (perhaps somewhat more than during the last ice-age but less than in the following warm-age)?

When our resources come closer to exhaustion or when they are increasingly threatened, we will be fighting over the remaining ones. The definition of limits to the utilization of nature has to reflect these social conflicts. But human society itself consists of population units and social systems that are differentially affected by resource shortages or by other environmental problems. Furthermore, issues are perceived and processed differently according to the interests, ratio, knowledge, and preferences of the individual sub-culture within society. Thus, it is even difficult to say what would constitute substantial ecological limitations to social reproduction:

- Shall the existential minimum of human dependency upon ecological resources serve as the yardstick, or shall the best possible accommodation of man's needs prevail?

- Shall the maximum stability or integrity of ecological systems be the criterion, or shall a boundary line be drawn, where ecological systems can be maximally utilized without being endangered? 
- Shall the risks and damages to the environment potentially affecting humankind be as small as possible, or shall dealing with the risks and damages be economically optimized?

For many environmental questions different approaches and answers are possible, and often they are controversial (cf. Marticke, this vol.). In principle the same is true about goals for the quality of life, concepts of ecological balance or their underlying models. This touches on the complications of the naturalistic fallacy. Is it possible to deduct from 'being' a 'should be', from the factual the normative, from the real the aspired, from the conditions of nature the conditions of culture? The fact that we are dealing always with cultural descriptions has to be taken into account. Our concepts of nature as well as our concepts of man and human culture are symbolical-linguistic units within communication processes and as such 'social constructions'. Every concept of nature has a cognitive dimension-it incorporates manifestations and principles of effect-as well as a normative dimension - by which nature is being judged beautiful or emaciated, violent or harmonious, and a practical dimension, that encodes (im)possible utilization forms, necessary restrictions to utilization, the value of ecological resources, useful or harmful substances. The practical dimension implies what to do in order to take care for a culturally altered 'natural' landscape, and to sustain its productivity in human terms.

\subsubsection{How to Build Integrative Goal Functions?}

The argumentative effectivity of goal functions, such as 'exergy' or 'ascendancy', or of more explicitly normative concepts, such as 'ecosystem integrity' or 'health', is quite different regarding their usefulness in science, their applicability in the management processes, or their quality in public discourse (cf. de Jong, this vol.). Additionally, the new goal functions concept has to demonstrate that it mediates better (with less costs; providing a more accurate basis for decisions) than competing approaches. What could be the function of goal functions in the negotiation of environmental alternatives and strategies? Environmental policy objectives are constructs, negotiated at the interface of science and politics, and stabilized in public discourse. The significance of deducing goal functions from dynamic structural models of ecological systems is not purely cognitive, because they contain interpretative claims to promote objectivistic environmental policy goals. Should this operation succeed, it would have the advantage, that protection goals and principles for the 'right' dealing with different ecosystems could be determined. They would be beyond the dispute of different interest groups. This path, however, is paved with several complications.

\footnotetext{
${ }^{4}$ Even the discrimination of conclusions from the factual to the normative isn't indeed a logical fixum or 'law' but a construction of a particular (modem) culture that has foregoing divided these two spheres of world's reality.
} 
In scientific modeling, goal functions are an instrument to describe system dynamics. It is one of the purposes of goal functions, to increase the prognostic capacities of models, especially, of ecosystem models. The transfer of this kind of elaborated scientific knowledge into practically useful management schemes generates a tendency to convert descriptive tools into prescriptive rules. This tendency is particularly worrysome because the definitions of goals or targets for individuals, for social and ecological systems are simultaneously affected by decisive cultural concepts. This is observable, e.g., in form of the diffusion of categories and ideas from physics and biology to economy and sociology, especially, whereas they appear in more general approaches, such as systems theory or synergetics (cf. Schwarz and Trepl, this vol.).

The idea of a legitimate integrative approach stands and falls with the proof that goals or goal functions exist for human individuals, social, economical and political systems, which are somehow compatible to ecosystemic goal functions. The following overview indicates some similarities.

- human individuals try ${ }^{5}$ - to keep alive, - to produce offspring, - to acquire a lot of goods, - to satisfy themselves (or each other) by sublimation and cultivation of abilities of self-expression (e.g., piano or cooking), or - to transcend of the mere boundaries of existence;

- social systems try - to prolong their self-reproduction,..., or - to free humankind from every burden by reaching (in Hegelian/Marxian terms) the 'realm of freedom' surpassing the 'realm of necessity', which is to be understood as a relict of natures' domination of man;

- economical systems try - to reproduce an economical unit, e.g., an enterprise, - to make profit, - to determinate a market, - to change financial in political power in order to determine (world) markets and to limit unwanted political influences or better: to control them;

- political systems try - to sustain their power, - to maintain a given order, - to administrate or solve problems, - to change from the domination of man to the administration of things, or - to make progress related to justice, democracy, welfare, etc.

Societies are not homogeneous units, however. Thus, a mediation of ecological goal functions and the goals of human societies has to recognize the functional and structural differentiation of modern societies (Parsons 1975, 1996). Societies consist of several sub-systems, such as the economical, political, scientific, and the juridical system, which have differentiated, heterogeneous and conflicting goals while following their particular operational logic (Luhmann 1984). The different sub-systems generate varying preferences and allow actors to interpret the targets of the social unit. Society does not have a given and accepted systemintrinsical goal definition.

SThis overview works without regard to the philosophical necessary distinctions between 'teleonomy' (non-intentional processes as for instance adaptation, that lead to effects that are to describe as goalaftainment) and teleology (intentional goal-attainment). 
The second problem of a unified goal function concept emerges on the level of organizations that have to integrate targeting conflicts. They are frequently forced to perform internal reforms by redefining their targets because their social environment changes. Profit maximization, for instance, is obviously a goal function of enterprises under conditions of a capitalistic economical system. But economic actors have to follow several, sometimes conflicting goals in realizing this target, e.g., to defend a market share against competitors, which may reduce short term profit.

The third and perhaps main problem deals with the contradictions emerging from of the different (but nested) reference systems of goal functions, namely: individuals $<>$ populations $<>$ societies $<>$ ecosystems. The first difference is well known in evolutionary theory and sociobiology: reproductive advantages for the species can be of disadvantage to the individual (Wilson 1975). It is as well known in social science, where classical economy and liberalism hold that economic egoism results in disadvantages to certain individuals, but still leads to public benefits. Ecosystems finally, which are composed of a huge number of different species, are as well a problem with their varying population numbers and community organizations: an advantage for one species must not be (per se) an advantage for the stability of the whole system of coevolving species. The situation becomes even more complicated if the competitive and cooperative interactions of all coexisting human societies in relation to the global ecological system are considered.

Fourth, we have to consider the difference of intentionally defined goals and the non-intentional development of goal functions. Besides all parallels, as selfconscious individuals we can define the goals of ourselves, and - in principle also of our societies and their institutional sub-systems and organizations. Natural systems may follow goal functions or perform an evolution that can be described as goal-attaining teleonomy, but social systems are in principle units, that are able - up to some degree - to enforce intended and directed developments, which can be described as real teleology. However, it makes sense to speak of sociocultural or societal evolution as an analytical tool in order to investigate not only the parallels but also the differences to biophysical evolution (Giesen and Lau 1981; Buihl 1984; Burns and Dietz 1992a, b). We can try to assimilate an increasing rate of energy and resources, to reduce the consumption of energy and resources, to adapt to the ecological environment, or to determinate the environment by active transformation. Observable strategies are certain combinations of these four main directions of eco-social rationality related to particular cultural ways of life (Metzner 1994). So even if we find (or agree upon) some goal functions common for ecological and social systems, their status would not be any longer one of an objectively given necessity, but a kind of ecologically informed, voluntarily chosen (that is: contingent) strategy. For each of them, other strategies are possible - but not in each case advisable - that have specific advantages and disadvantages. 
Selecting appropriate strategies is a process of measuring up alternatives, governed by value judgments. According to this realization we could say that it is in no way better to ask science alone for guidance than using a divining rod to find out the primary goal function out of a list of several relevant items, such as 'exergy', 'ascendancy', 'integrity', 'resilience', 'stability' or 'human happiness'. 'Non-sense', 'prejudice' or 'in-genious' - my divining rod and I, we chose human happiness. In the social discourse about which characteristics of nature should be preserved, immutably, we have to deal with different views of nature and the source of its value: functional or aesthetic; anthropocentric or physiocentric. In view of these difficulties, one can justifiably argue that it is impossible to set 'objective' environmental management or policy goals. In this context I do not support an epistemologically radical position, biased either to relativistic constructionism or to positivistic objectivism, but a pragmatically oriented, socio-ecologically reflected realism.

It is as possible and meaningful to build indicators that try to express, e.g., ecosystem health related to the potential to follow goal functions, as of pollution limits that indicate risks to human health or to the utilization of ecological resources. These indicators can be determined in an objectivistic way, and play an important role in the communication and negotiation process within the triangle of sciences, politics and the general public. However, any scientific 'claim' to represent objective truth remains problematic and is not self-evident. Scientific knowledge has to establish itself in interdisciplinary and public discourses, gaining strength from orientational and instructional practicability and effectivity. According to this position, the value of a unifying goal function concept lies rather in its orientational usefulness and not so much in its quantitative utilization. The quantification is of limited value because any complete framing has to integrate goal functions of different classes of parameters that cannot be optimized mathematically in an obvious sense, as for instance, by means of the Pareto-optimality (cf. Gnauck Sect. 5.6). Consequently, value judgments that measure different classes or dimensions, e.g., aesthetical needs, economical needs, preservation of species, security against floods, etc., are not avoidable. There is no way to solve these targeting conflicts using only arithmetical means. The conflicts are to be dealt with psycho-socially by negotiation and mediation. In rare cases, when all affected actors agree upon procedures, indicators and the particular integration of all relevant factors, the use of mathematical decisionmodels is proper and can lead to success.

In terms of the social promotion of environmental knowledge, the goal function concept seems too general or indifferent to advertise politicians, and too complex for public discourse and the mass media. Instead, the more compact terms of eco-systems integrity or health - to which goal functions can be related - do not only sound better but seem to provide that kind of orientational knowledge that is demanded in policy and public discourse. 


\subsubsection{Conclusion}

Recent efforts to encounter the environmental crisis often appear as a kind of 'muddling-through' strategy concentrating on crisis management or the appeasement of conflicts by means of symbolical policy instead of focusing on problemsolving. Consequently, it is decisive to develop orientational approaches and to work out strategies that connect the debates over technology, economy and the environment. We have to look at real world problems and to integrate the concerned population into the discussion about development perspectives, concrete projects and problem-solutions. Besides all mentioned problems, ecological goal functions seems to provide a scientific basis for the evaluation of ecosystem states and developments. They may be highly useful in the continuous process of balancing human (settled) targets with natural (pre-existing, self-organizing) system targets, especially, if they are related to more general models of ecological integrity or health.

It remains a huge theoretical problem, however, how to link analyses of actor oriented studies (working under premises of methodical individualism) and studies based on systems theory that reconstruct functions independently of the action-leading motives of actual persons by lifting the level of abstraction to more general concepts (like equilibrium or homeostasis, stability, resilience, reproduction, self-maintenance, growing and differentiation of complexity, etc.).

Even though interdisciplinary study is necessary and imperative, it is often treated as a mere statement of good will. The various possibilities to interpret and misunderstand specialized expressions (e.g., 'labor' as a category in physics or in the social sciences) poses a serious problem to interdisciplinary work, manifesting itself in short circuited popular theses (e.g., the prolongation of thermodynamics to concepts of 'social entropy'). Another problem is created by the "ontological" way to draw distinctions between scientific, particularly ecological, objects, which becomes increasingly obsolete in face of global ecological problems. The relationship between natural and technological sciences, the social sciences and the humanities needs further clarification. We need to look at things not just from two angels but from four. Programs that are oriented towards unified sciences promoting one scientific view and neglecting others will hardly help. A simple 'as well as' approach, however, is neither satisfactory. Working together in a method- and issue-oriented way points in the right direction (as exemplified by the 'goal functions workshop').

Obviously, one can tackle problems under legal, economical, political, or scientific aspects. In order to promote processes of decision-making, it is important to mediate the use of the different problem concepts and solution styles. It is characteristic for the discourse about environmental problems and technological risks that it is reactively oriented towards negative consequences of industrial projects. It is not oriented towards approaches that try to shape future developments, for instance, by working with expectations and whole scenarios. However, even the re-active approach tries to include social, societal and ecological 
aspects as well as cultural and psychological ones. However, re-active approaches do characteristically assume that all aspects are quantitatively comparable in order to determine the optimal decision. It is evident, however, that a common measure for all aspects, e.g., by monetarization, is difficult to construct. Each concept that is used to promote social problem solving capacities should be aware that not a contradiction-free system of ideas is in question, but systems of social practice that escape 'pure' abstraction a good part of the way.

\section{References}

Alcamo J (1984) Acid rain in Europe: a framework to assist decision making. International Institute for Applied Systems Analysis, Working paper 32, Laxenburg

Ayres RU, Simonis UE (ed) (1992) Industrial Metabolism - Restructuring for Sustainable Development. United Nations University Press, Tokyo

Bailey R (ed) (1995) The True State of The Planet. Free Press, London, Toronto

Bechmann G et al. (1996) Sozialwissenschaftliche Konzepte einer interdisziplinären Klimawirkungsforschung. Forschungsbericht für das BMBF, Forschungszentrum Karlsruhe

Beck U (1986) Risikogesellschaft - Auf dem Weg in eine andere Moderne. Suhrkamp, Frankfurt/Main

Beck U, Giddens A, Lash S (1994) Reflexive modernization: Politics, Tradition and Aesthetics in the Modern Social Order. Polity Press, Cambridge

Brakel M van, Builtenkamp M (1992) Action Plan Sustainable Netherlands - A perspective for changing nothern lifestyles. Friends of the Earth Netherlands, Amsterdam

Bühl WL (1984) Gibt es eine soziale Evolution? Zeitschrift für Politik 31:302-332

BUND, MISEREOR (eds) (1996) Zukunftsfähiges Deutschland. Ein Beitrag zu einer global nachhaltigen Entwicklung. Studie des Wuppertal Instituts für Klima, Umwelt, Energie. Birkhäuser, Basel Boston Berlin

Burns TR, Dietz T (1992a) Technology, Social-Technical Systems, Technological Development, An Evolutionary Perspective. In: Dierkes M, Hoffmann U (eds) Technology at the Outset. Suhrkamp, Frankfurt/Main

Burns TR, Dietz T (1992b) Cultural Evolution: Social Rule Systems, Selection and Human Agency. International Sociology 7(3):259-283

Constanza R, Daly H, Bartholomew JA (1991) Goals, Agenda and Policy Recommandations for Ecological Economics. In: Constanza (ed) (1991) Ecological Economics. The Science and Management of Sustainability. New York

Douglas M, Wildavsky A (1988) Risk and Culture. 2nd ed., Berkley, Los Angeles London

Dunlap RE (1993) From Environmental to Ecological Problems. In: Calhoun C, Ritzer G (eds) Social Problems, McGraw-Hill, NewYork, pp 707-738

Dunlap RE, Catton WR jr. (1994) Toward an ecological sociology: the development, current status, and probable future of environmental sociology. In: D'Antonio WV, Sasaki M, Yonebayashi Y Ecology, Society \& the Quality of Social Life, New Brunswick, London, pp 11-31

Fischer-Kowalski M (1991) Was ist ökologisch verträglich? - Über die Schwierigkeiten der Verständigung. In: Geyer A, Getzinger G (ed) Chemie und Gesellschaft - Ansätze zu einer sozial- und umweltverträglichen Chemiepolitik. München, pp 143

Fowlkes MR, Miller PY (1987) Chemicals and Community at Love Canal. In: Johnson BB, Covello VT (ed) The Social and Cultural Construction of Risk - Essays on Risk Selection and Perception. Kluwer Academic Press, Dordrecht, pp 55-78

Giesen B, Lau C (1981) Zur Anwendung darwinistischer Erklärungsstrategien in der Soziologie. In: KZSS 33:229-256 
Gras A (1993) Grandeur et Dépendance - Sociologie des macro-systèmes techniques. PUF, Paris

Hannigan JA (1995) Environmental Sociology, a social constructionist perspective. Routledge, London New York

Hansen A (1993) Greenpeace and press coverage of environmental issues. In: Hansen A (ed) The Mass Media and Environmental Issues. Leicester

Huber J (1995) Nachhaltige Entwicklung - Strategien für eine ökologische und soziale Erdpolitik. Sigma, Berlin

Japp KP, Krohn W (1996) Soziale Systeme und ihre ökologischen Selbstbeschreibungen. Zeitschrift für Soziologie 3:207-222

Jungermann H, Slovic P (1993) Charakteristika individueller Risikowahmehmung. In: Krohn W, Krücken G (eds) Riskante Technologien: Reflexion und Regulation - Einführung in die sozialwissenschaftliche Risikoforschung. Suhrkamp, Frankfurt/Main, pp 79-100

Krohn W, Küppers G, Paslack R (1987) Selbstorganisation - Zur Genese und Entwicklung einer wissenschaftlichen Revolution. In: Schmidt SJ (ed) Der Diskurs des Radikalen Konstruktivismus. Suhrkamp, Frankfurt/Main, pp 441-465

Lash S, Szerszinsky B, Wynne B (1996) Risk, Environment and Modernity, Towards a New Ecology. Sage, London Thousand Oaks New Delhi

Leakey R, Lewin R (1993) Der Ursprung des Menschen. Fischer, Frankfurt/Main

Löther R (ed) (1988) Tiersozietäten und Menschengesellschaften - Philosophische und evolutionsbiologische Aspekte der Soziogenese. Fischer, Jena

Luhmann N (1984) Soziale Systeme. Westdeutscher Verlag, Opladen

Luhmann N (1986) Ökologische Kommunikation. Westdeutscher Verlag, Opladen

Luhmann N (1991) Soziologie des Risikos. De Gruyter, Berlin New York

Maxeiner D, Miersch M (1996) Öko-Optimismus. Metropolitan Verlag, Düsseldorf

Mazur A (1991) Putting Radon and Love Canal on the Public Agenda. In: Couch SR, KrollSmith IS (eds) Communities at Risk - Collective Responses to Technological Hazards. Lang, New York San Francisco Bern Frankfurt/Main Paris London, pp 183-203

Metzner A (1993) Probleme sozio-ökologischer Systemtheorie - Natur und Gesellschaft in der Soziologie Luhmanns. Westdeutscher Verlag, Opladen

Metzner A (1994) Offenheit und Geschlossenheit in der Ökologie der Gesellschaft. In: Beckenbach F, Diefenbacher H (eds) Zwischen Entropie und Selbstorganisation: Perspektiven einer ökologischen Ökonomie. Metropolis Verlag, Marburg, pp 349-391

Metzner A (1997) Konstruktion und Realität von Umwelt- und Technik-Risiken - Ansätze sozialwissenschaftlicher Risikoforschung. Zeitschr $f$ angewandte Umweltforschung, in print

Mol APJ (1995) The Refinement of Production, Ecological Modernization Theory and the Chemical industry. Van Arkel, Utrecht

Parsons T (1975) Gesellschaften - Evolutionäre und komparative Perspektiven. Suhrkamp, Frankfurt/Main

Parsons T (1996) Das System moderner Gesellschaften. Juventa-Verlag, Weinheim, p 200

Perrow C (1984) Normal accidents-Living with high-risk technologies. Basic Books, New York Popper KR (1982) Logik der Forschung, 7th edn.. Mohr, Tübingen

Prigogine I, Stengers I (1981) Dialog mit der Natur - Neue Wege naturwissenschaftlichen Denkens. Piper, München Zürich

Schluchter W, Metzner A (1996) Globalization, Environmental Awareness, and Ecological Behavior shown at the Example of the Federal Republic of Germany. In: Ester P, Schluchter W (eds) Global Development of Societies and Environment. Tilburg Univ Press, Tilburg

Spector M, Kitsuse JI (1987) Constructing Social Problems. Wiley, New York

Thompson M, Ellis R, Wildavsky A (1990) Cultural Theory. Colorado, Oxford

Ungar $S$ (I992) The rise and (relative) decline of global warming as a social problem. The Sociological Quarterly 33:483-501 
WCED (World Comission on Environment and Development) (ed) (1987) Our Common Future. Oxford University Press, Oxford NewYork

Weichhart P (1989) Werte und Steuerung von Mensch-Umwelt-Systemen. In: Glaeser B (ed) Humanökologie - Grundlagen präventiver Umweltpolitik. Westdeutscher Verlag, Opladen, Weingart P (1983) Verwissenschaftlichung der Gesellschaft - Politisierung der Wissenschaft. In: Zeitschrift für Soziologie 12:225pp

Wildavsky A (1995) But is it true? - A Citizen's Guide to Environmental Health and Safety Issues. Harvard University Press, Cambridge, London

Wilson EO (1975) Sociobiology - The New Synthesis. Cambridge London 